\title{
Tunneling and Monitoring in Chinese Share Market
}

\author{
Zhong Qin $^{1} \&$ Qiao Wang ${ }^{2}$ \\ ${ }^{1}$ School of Business, Shantou University, Shantou, China \\ ${ }^{2}$ Graduate School, Shantou University, Shantou, China \\ Correspondence: Zhong Qin, School of Business, Shantou University, Shantou 515063, Guangdong, China. Tel: \\ 86-754-8650-4177. E-mail: zqin@stu.edu.cn \\ Received: February 23, 2013 \\ Accepted: April 4, 2013 \\ Online Published: June 30, 2013 \\ doi:10.5430/rwe.v4n2p28 \\ URL: http://dx.doi.org/10.5430/rwe.v4n2p28
}

This research is sponsored by the fund from Project of Guangdong Provincial $12^{\text {th }}$ Five-Year Plan of Philosophy and Social Science, China.

\begin{abstract}
There has been ample evidence suggesting that "tunneling" or expropriation of minority shareholders by the controlling shareholders has been a serious problem in the share market in China. This remains the case, despite the fact that the share division arrangement has been discontinued, and shares owned by different shareholders are now treated equally in share market (full circulation). Empirical studies suggest that improved legal protection of investors and enhanced regulation are efficient and essential measures to restrict tunneling. There are, however, few studies that have explored this topic theoretically. Aiming to fill this gap in the literature, this paper sets up a mixed-strategy game between the regulator (the China Securities Regulatory Commission (CSRC)) and a controlling shareholder of a representative company to analyze the strategies of both sides and investigate factors that may curb tunneling. Based on the model, recommendations on how to restrict expropriation of minority shareholders are presented. Results from this model provide theoretical support for empirical studies.
\end{abstract}

Keywords: tunneling (Note 1), regulation, game theory, China

\section{Introduction}

\subsection{Share Market in China and Share Division}

September 26, 1986 is a notable date for China's capital market. The first security transaction counter, Jingan Security Business Department, was opened for business on that date, marking the birth of China's share market after economic reform. December 1990 saw the opening of the Shanghai Stock Exchange, followed by the opening of the Shenzhen Stock Exchange in July 1991. The two stock exchanges subsequently led the way in the accelerated development of the share market in China.

The share market was introduced as a trial to explore the viability of a socialist market economy, and share division is a by-product of this trial. Under this arrangement, shares were classified into state shares, institutional shares and public shares. Only public shares could be traded in the share market, and shares owned by the state and institutions were not tradable. The restriction on liquidity of the shares has led to different prices and different rights for different categories of shares. Share division has also led to a dualistic market where different shares are traded under different market mechanisms and structures as well as different trading practices.

It is worthwhile to discuss the background that generated the share division arrangement. China introduced the shareholding system to restructure state owned enterprises (SOEs) from the late 1980s to the early 1990s. The main objective of the restructuring was to establish a modern enterprise system and to improve corporate governance of the SOEs. As a result, one of the major objectives underlying the establishment of the share market was to facilitate the restructuring of the SOEs. There were concerns about shareholding reform and the security market, such as whether issuing shares would lead to privatization, whether it would cause the loss of state assets, and whether the dominating status of state ownership over the national economy would be affected. A compromise proposal was introduced to address these concerns. The state assets were transformed into non-tradable shares (including state shares and state institutional shares). This resulted in the creation of four types of shares in the security market in 
China: state shares, institutional shares, individual shares and foreign shares. The last two are also called public shares and can be traded in the stock exchange when the company is listed. State and institutional shares, however, are "temporarily" non-tradable. This unique arrangement is called "share division" or "equity division" in China.

This dualistic share structure has caused many problems. Controlling shareholders (who normally own non-tradable shares), for example, do not care about the share price as they cannot sell their shares in the share market. They are motivated to take actions that benefit themselves but may injure the interests of the company and all other shareholders, such as transferring profit out of the company and using the company as guarantors for bank loans of other related companies. Some controlling shareholders have even considered public shareholders an "ATM", and have treated their money as "charity contributions" at no cost. The development of the share market is severely affected as a result.

The reform of share division took place on April 30, 2005, and was completed in September 2006. The essence of share division reform was to allow all of the shares to be traded in the same stock exchange under the same trading rules, in an arrangement called "full-circulation". It was expected that full-circulation would diminish tunneling activities and allow the share market to resume its normal function. Indeed, share division reform was considered to be the driving force of the bull market in China in 2007, and total value of the share market exceeded GDP in China for the first time that year. The year of 2007 has been considered a remarkable year in the history of the share market in China.

\section{2 "Tunneling"}

Past research indicates that controlling shareholders of listed companies use various methods to expropriate minority shareholders during the period of share division. These methods include appointing directors and managers, interfering with production and daily operations, taking up resources via affiliate transactions, impropriating funds and assets of the company, and manipulating companies to disclose false information.

In this paper, we follow Johnson et al (2000) to define "tunneling" as transferring assets and profits out of firms for the benefit of those who control them. More precisely, tunneling refers to the diversion of corporate resources from the corporation to the controlling shareholders. Johnson et al (2000) listed a variety of forms tunneling can take, including expropriation of corporate opportunities from a firm by its controlling shareholders, transfer pricing favoring the controlling shareholders, transfer of assets from a firm to its controlling shareholders at non-market price, and loan guarantees using the firm's assets as collateral. Apart from real transactions, share diluting has also been utilized as a financial form of tunneling. Tunneling may also take the form of theft or fraud, particularly in emerging markets. While some tunneling activities are legal even in developed countries, they are challenged on fairness grounds by minority shareholders, given that they are always the victims of such activities.

Researchers have produced ample evidence of tunneling. Tang and Jiang (2002) conducted an empirical analysis on expropriation of minority shareholders by large shareholders in listed companies in China, and found that the smaller companies are less transparent, and their minority shareholders are more likely to be expropriated. Liu and He (2004) discovered that methods including high dividend payments, affiliate transactions, and direct and indirect encroachment are widely used by large shareholders to gain interests from listed companies. A study by Li et al (2004) further reveals that ownership structure is related to the degree of expropriation. Some scholars regard "tunneling" to be a result of the absence of laws and regulations to protect small and medium investors and weak monitoring by government agencies. For example, Bing and Shu (2003) consider it misleading to blame share division for problems of the share market in China, and they believe that the key issue is the lack of an effective mechanism to protect investors and to restrict expropriation by government, large shareholders and management. Still, share division was blamed as the source of problems. Under the share division arrangement, listed companies often have a single large shareholder, and issue shares with different rights and different prices. Such practices are believed to have led to "greed" of controlling shareholders and to have provided a convenient means for them to "tunnel".

Share division reform, however, has not provided answers for many questions. Will regulators be relieved of the need to strengthen regulations by allowing all shares be treated equally in share market? According to economic theory, under the modern corporate system, what shareholders obtain is the remaining profit of the company, or the right to residual claim. It is, indeed, the right to claim future cash flow generated by the firm. In reality, due to the separation of control right and the right of residual claim, controlling shareholders will take advantage of their control right to "tunnel" resources away from the company at the expense of minority shareholders so as to maximize their own interest. Meanwhile, mainstream research in property rights economics suggests that property owners will protect themselves by encroaching on resources when the institutional arrangement of a nation cannot effectively ensure 
property owners can realize their return. Empirically, research by Shleifer \& Wolfenzon (2002) and Lins (2003) shows that expropriation of minority shareholders also happens in developed countries whose share market allows full circulation of all shares in the market. Huang (2006) sets up a game of large shareholders encroaching on resources, and tests the model with all listed companies in China. He concludes that large shareholders still have a strong incentive to encroach the company's resources even if share ownership is extremely dispersed (full circulation). The above research indicates that tunneling remains an issue even in a share market where shares are fully circulated, as large shareholders will expropriate minority shareholders to maximize their own interest. In fact, under a full circulation arrangement, games of interest, operation and market environment in the capital market will be much more complicated. As a result, strategies and behaviors of listed companies will be influenced significantly, and regulators will face new challenges.

\subsection{Monitoring}

Obviously, the reform of share division cannot solve the problem of tunneling. Therefore, the focus should be shifted to how to restrict tunneling and protect small and medium investors via laws and regulations. Recently, following ground-breaking research by La Porta and others (La Porta, et al. 1999; La Porta, et al. 2000; 2002; La Porta, et al. 1997), more and more scholars have shifted the focus of their research from internal governance to the impact of the external environment on corporate governance. One area of investigation is the legal protection of external investors and the firm's ownership structure, value of the firm and development of the capital market. Relatively speaking, it has been found that nations that provide better protection of external investors have a more developed share market, have more listed companies, have listed companies with higher market value, that listed companies will distribute more cash dividend and that the ownership and control are relatively dispersed (La Porta, et al.1997, 1999, 2000, 2002).

The major conclusions drawn from research conducted in China on investor protection include: (a) Government needs to enact laws and regulations to protect minority shareholders to resolve the conflict of interest between large shareholders and minority shareholders (Yan and Zhou 2007), (b) An investor protection system is useful in reducing financing costs, as good investor protection can effectively alleviate information asymmetry and agency issues between insiders of the company and external stakeholders (Xiao and Shen 2008), (c) A transparent legal and market environment will effectively stop tunneling (Luo and Tan 2007), and (d) Investor protection may also discourage controlling shareholders' tunneling activities (Gao, et al. 2006).

It is not difficult to conclude from the review of literature that an improved investor protection system can protect the interest of small and medium investors as well as benefit the listed companies. However, most studies on investor protection in China are based on empirical analysis and few have developed theoretical models.

The China Securities Regulatory Commission (CSRC), established in 1992, is the only regulator of the share market in China and oversees all security-related activities. Its major functions include monitoring the security market according to relevant laws and regulations, maintaining orderly operation of the market, and promoting relevant laws and regulations on the share market. As a result, we can construct a game to be played between controlling shareholders of listed companies and the CSRC as a regulator. This paper will use a game to analyze strategies that may be adopted by each player, and to explore factors that may curb tunneling activities. This study will fill the theoretical gap of research on tunneling and attempt to identify effective measures to protect small and medium investors.

\section{Assumptions}

Before discussing the details of the game, the basic assumptions of the game are presented.

Assumption One: The game is a repeated simultaneous game with two players: the CSRC and a controlling shareholder of a representative listed company.

Assumption Two: Both players are rational, aiming to maximize their own interests.

The controlling shareholder is motivated to tunnel as it can receive a return that is much higher than the return it can normally receive from the share market.

Assumption Three: The controlling shareholder has control and information advantage. They are capable of expropriating minority shareholders via tunneling, and obtain benefits at the costs of the company and minority shareholders.

Meanwhile, we assume that the CSRC can discover whether controlling shareholders have expropriated minority shareholders or not via inspecting a company. 
Strategies available for the CSRC are Inspect and Don't Inspect, and strategies available for the controlling Shareholder are Encroach and Don't Encroach.

Payoffs of the two players: if the controlling shareholders encroach, their payoff is $r$; if the controlling shareholder does not encroach, and the CSRC does not inspect, their payoff is 0. Assuming the costs for CSRC to inspect is $c$, and if found guilty, controlling shareholders are required to pay a penalty of $k$, and also surrender back their gain of $r$. The CSRC also gain reputation that is equivalent to $M$. As a result, the net payoff for CSRC is $k+r+M-c$. Meanwhile, if the controlling shareholder's tunneling activities were discovered by the CSRC, their actual loss is paying a penalty of $k$ and losing reputation of $m$. As a result, their net gain is $-k-m$, where $m$ is reputation of the controlling shareholders. If inspection by the CSRC reveals no encroachment activities in the company, controlling shareholders will receive a reputation gain of $m$ for good corporate governance. Given that there are about 2000 listed companies in China, it is not possible for the CSRC to inspect every company. Due to high inspection costs, it will only spot check or inspect a company when tunneling activities are reported. However, if it fails to inspect a company whose controlling shareholders injure the interest of the listed companies, the negative perception by the public will damage its reputation which results in a loss of $M$ for the CSRC (Note 2).

Assumption Four: We assume the probability of being inspected is $p$, or the probability of not being inspected is $(1-p)$. The probability of the controlling shareholder to encroach is $q$, and the probability of not encroaching is (1-q).

The payoff matrix is shown in Table 1:

Table 1. The payoff matrix between the CSRC and a controlling shareholder

\begin{tabular}{lcccc}
\hline & & \multicolumn{2}{c}{ Controlling Shareholder } \\
\cline { 2 - 4 } CSRC & Inspect: $\quad \mathrm{p}$ & $(\mathrm{k}+\mathrm{r}+\mathrm{M}-\mathrm{c},-\mathrm{k}-\mathrm{m})$ & Not Encroach 1-q \\
\cline { 2 - 4 } & Not Inspect: & $1-\mathrm{p}$ & $(-\mathrm{M}, \mathrm{r})$ & $(-\mathrm{c}, \mathrm{m})$ \\
\hline
\end{tabular}

From the game matrix above, we can identify optimal strategies for each player under different occasions. If the CSRC inspects, the best strategy for the controlling shareholder is not to encroach, and gain a positive payoff of $m$ as compared to a negative payoff $(-k-m)$. If the CSRC does not inspect, the best strategy for the shareholder is to encroach and gain a payoff of $r$ as compared to a payoff of zero. On the other hand, if the controlling shareholder does not encroach, then the CSRC can save their inspection costs by not inspecting. It is a bit tricky to identify CSRC's strategy in case the controlling shareholder encroaches. Being a rational player, the CSRC will inspect only if $k+r+M-c>-M$, or $k+r+2 M>c$. In other words, if $k+r+2 M<c$, "not inspect" will become dominant strategy for the CSRC, and game is solved with a Nash Equilibrium of (Not Inspect, Encroach).

However, this is unlikely to be the case in the real world. First of all, inspecting and monitoring listed companies is one of the major roles played by the CSRC. If "not inspect" becomes a dominant strategy, it indeed suggests that there is no need for the CSRC to exist, or its role needs to be re-defined. Besides, it is not unreasonable to assume $k$ $+r>c$. Given that it is unlikely for a regulator to discover all illegal activities, the penalty is normally set at a level that is significantly higher than the gain of violating the regulation to deter such activities. In other words, $k$ is significantly higher than $r$. If $k+r \leq c$, it means that the cost of inspection is more than double the gain obtained by the controlling shareholder. If the inspection cost is very high compared to the gain (which should be substantially large to induce the controlling shareholder to violate the regulation), it is perhaps not worthwhile for the CSRC to inspect a company. Alternatively, if it can be argued that inspection is warranted to deter future tunneling activities, then an obvious remedy for the CSRC is to increase the penalty $(k)$ to a level that is at least high enough to cover the costs of inspection.

Therefore, we are unable to find a pure strategy Nash Equilibrium. Instead, we can only try to identify a mixed strategy Nash Equilibrium.

\section{Analysis of the Game between the CSRC and a Controlling Shareholder}

\subsection{Mixed Strategy Nash Equilibrium}

\subsubsection{Identify $q$}

Assuming that both players are risk neutral, we can find the Nash Equilibrium where each player receives the same expected payoff from both strategies. As a rational player, the CSRC will inspect only if its expected payoff is higher than the payoff of not inspecting. 
If the CSRC inspects, its expected payoffs are:

$$
\mathrm{E}(\text { Inspect })=\mathrm{q}(\mathrm{k}+\mathrm{r}+\mathrm{M}-\mathrm{c})-(1-\mathrm{q}) \mathrm{c}
$$

If the CSRC does not inspect, its expected payoffs are:

$$
\mathrm{E}(\text { Not Inspect })=-\mathrm{q} M
$$

By equating the CSRC's expected payoffs, i.e. $\mathrm{E}($ Inspect $)=\mathrm{E}($ Not Inspect), we have

$$
\mathrm{q}^{*}=\mathrm{c} /(\mathrm{r}+\mathrm{k}+2 \mathrm{M})
$$

In other words, if the probability of encroachment of the controlling shareholder is higher than $c /(r+k+2 M)$, the CSRC receives higher expected payoffs by inspecting. Therefore, the optimal strategy for the CSRC is to inspect. On the other hand, the CSRC will be better off not inspecting if the probability of encroaching is smaller than $\mathrm{c} /(\mathrm{r}+\mathrm{k}+$ $2 \mathrm{M})$. If the probability of encroachment is exactly $\mathrm{c} /(\mathrm{r}+\mathrm{k}+2 \mathrm{M})$, the CSRC is indifferent between inspection and no inspection.

\subsubsection{Identify $p$}

If the controlling shareholders encroach, their expected payoffs are:

$$
\mathrm{E}(\text { encroach })=-(\mathrm{k}+\mathrm{m}) \mathrm{p}+(1-\mathrm{p}) \mathrm{r}
$$

If the controlling shareholders do not encroach, their expected payoffs are:

$$
\mathrm{E}(\text { not encroach })=\mathrm{pm}
$$

By equating the controlling shareholders' expected payoff, or $\mathrm{E}(\mathrm{encroach})=\mathrm{E}($ not encroach), we have

$$
\mathrm{p}^{*}=\mathrm{r} /(\mathrm{k}+\mathrm{r}+2 \mathrm{~m})
$$

In other words, if the probability of being inspected by the CSRC is smaller than $r /(k+r+2 m)$, the controlling shareholder's optimal strategy is to encroach; if the probability of being inspected by the CSRC is larger than $r /(k+$ $r+2 m$ ), the controlling shareholders' optimal strategy is not to encroach. If the probability of being inspected by the CSRC is $r /(k+r+2 m)$, controlling shareholders are indifferent between the two strategies.

Therefore, the Nash Equilibrium of the game is $\left(q^{*}, p^{*}\right)=[c /(r+k+2 M), r /(k+r+2 m)]$. The change of each variable influencing two players' decisions will be discussed below.

\subsection{Factors Influencing Players' Decisions}

\subsubsection{Increase $k$ while Holding Other Variables Constant}

$q^{*}$ is negatively related to $k$. If we hold constant the return of encroachment $r$, inspection costs $c$, and reputation gain $M$, an increase in $k$ will reduce $q^{*}$. In other words, a more severe punishment imposed by the CSRC will lead to a higher loss to controlling shareholders if they are found guilty of encroachment activities. As a result, their expected payoff will decrease and they are less tempted to encroach.

$p^{*}$ is negatively related to $k$. If we hold $r$ and $m$ constant, a larger $k$ will also result in smaller $p^{*}$. This is because controlling shareholders will be punished more harshly if they are found guilty of encroaching. Therefore, their expected payoff is smaller, their willingness to encroach is lower, and the probability of encroaching is also smaller. As a result, the CSRC may inspect less frequently and reduce the costs of inspection.

Therefore, we have

Proposition 1: More severe punishment can lead to a lower probability of encroachment by controlling shareholders, better protection of small and medium shareholders, and administrative cost savings to the CSRC.

\subsubsection{Increase $r$ while Holding Other Variables Constant}

$q^{*}$ is negatively related to $r$. Holding $k, c$ and $M$ constant, an increase in $r$ will lead to smaller $q^{*}$. Since $r$ is the return received by controlling shareholders through encroachment, an increase in $r$ by controlling shareholders will generate two consequences: on the one hand, a listed companies' operation and performance will be negatively affected by the fact that a large amount of the company's resources are taken by the controlling shareholder. Companies may end up with a loss for a lengthy period of time. In China, the ST system is in place in the share market and loss-making companies may be de-listed (Note 3). A company needs to meet strict requirements regarding performance if it wants to issue new shares to raise more funds from the market. Besides, poor performance will see investors "voting with their feet" or dumping the shares of the company, which will also lead to high financing costs in the future. On the other hand, severe encroachment may be reported to either media or the 
CSRC, who will inspect the company. Trading off different interests, controlling shareholders prefer to "nibble" listed companies and gain more benefits in the longer term. Therefore, our model shows that $q^{*}$ is smaller when $r$ is larger, and $q^{*}$ increases when $r$ is smaller. The above analysis is consistent with the empirical analysis by Friedman et al (2003) which suggests that controlling shareholders are more likely to support the company when the latter is in debt crisis. They expect to gain more benefits in the future after supporting companies through crisis. Moreover, Jensen \& Meckling (1976) suggest that external investors can protect themselves via "voting with their feet". Controlling shareholders have to restrict their tunneling activities.

After rearranging equation (6) we have

$$
\mathrm{p}^{*}=1 /(\mathrm{k} / \mathrm{r}+2 \mathrm{~m} / \mathrm{r}+1)
$$

The higher $r$ is, the higher $p^{*} . p^{*}$ is positively related to $r$. Holding $k$ and $c$ constant, an increase in $r$ will lead to a higher $p^{*}$, or higher inspection frequency. The reason is that the more controlling shareholders gain from encroachment, the more damage it imposes on the share market. After the game has been repeated several times, the CSRC will form an expectation on encroaching activities and is more likely to inspect listed companies in the future.

Therefore, we have

Proposition 2: Rather than engaging in extensive tunneling within a short period of time, controlling shareholders tend to "nibble" at listed companies so as to gain more benefits in the longer term.

\subsubsection{Increase $m$ and $M$ while Holding Other Variables Constant}

An increase in $M$ and $m$ will lead to smaller $q$ and $p$. The more the CSRC cares about its reputation, the more it wishes to curb controlling shareholders' tunneling activities. This is because controlling shareholders will develop an expectation of inspections from the CSRC after the game has been repeated several times. If their tunneling activities are discovered and reported by the media, the negative publicity will affect both the company and the CSRC. The CSRC will be regarded as incompetent, will incur a loss in reputation, and it will impose a harsher punishment on tunneling activities.

Following the same logic, the more the controlling shareholders care about their reputation, the less likely the CSRC will inspect the company, as the latter can save administrative costs by doing so. This is because the CSRC will form an expectation that controlling shareholders will restrict their tunneling activities if they care about their own reputation. The tunneling activities may be publicized by investors or media, and the negative publicity will damage their image as well as that of the companies, resulting in higher financing costs in the capital market which will work against their long term development. This result is consistent with the argument by Williamson (1993) that concern for reputation serves as a check on opportunism. It is not difficult to realize the important role played by the media in regard to curbing tunneling. The media reporting on performance of the CSRC and tunneling activities will create pressure from public opinion, will force the CSRC and the controlling shareholders to pay attention to their reputation, and will reduce tunneling activities. Results from the discussion above are consistent with an empirical study by Dyck et al (2008) which reports on the effect of media coverage on corporate governance by focusing on Russia in the period 1999 to 2002. They found that coverage in the Anglo-American press increased the probability that a corporate governance violation is reversed.

Therefore, we have

Proposition 3: Media coverage on tunneling activities can curb tunneling activities by controlling shareholders.

\subsubsection{Reduce $c$ while Holding Other Variables Constant}

Smaller $c$ or inspection costs (direct ways to cut down inspection costs include improving technology and allocating more resources to the inspection department) will lead to smaller $q^{*}$. Lower costs will increase the CSRC's willingness to inspect. Controlling shareholders' chances of being penalized is much higher if they persist in their encroachment activities. Hence, their expected payoff will be lower and their willingness to encroach will be lower, which is reflected by a lower $q^{*}$. It is essential to improve technology and reduce inspection costs.

Therefore, we have

Proposition 4: Controlling shareholders' encroachment activities can be curbed by allocating more resources to the monitoring department and reducing monitoring costs.

\section{Discussion and Implications for the Security Market in China}

Tunneling is not only a serious issue in developing countries (markets), but also widely exists in developed countries (markets) (Johnson, et al. 2000; Shleifer and Wolfenzon, 2002). There are plenty of empirical studies suggesting 
improved legal protection of investors and enhanced external monitoring are both necessary and effective measures to curb tunneling. There are, though, few studies that have explored this issue from a theoretical perspective. Utilizing a repeated static game between the CSRC and a controlling shareholder, this paper analyzes and investigates factors that may curb tunneling. Especially, we explored the impact of reputation on tunneling and present an alternative measure to address tunneling in an Asian country like China.

Based on the above model, we believe that regulators may improve corporate governance of listed companies via adopting the following strategies which will reduce tunneling and protect the interests of small and medium investors.

\subsection{Reinforce Monitoring and Increase Punishment}

The CSRC should be allowed to lay criminal charges against tunneling including controlling shareholders using company's funds, insider-trading and affiliate transactions. More severe punishment needs to be used to deter tunneling.

\subsection{Reinforce Monitoring by Media and Investors}

Media reports on expropriation of minority shareholders will impose pressure on the CSRC and force it to take action. Investors themselves also need to monitor listed companies and report controlling shareholders' encroachment activities to the CSRC and the media. The CSRC may consider publishing the names of shareholders who are responsible for tunneling on its website as well as feeding such information to the media on a regular basis.

\subsection{Enhance the Ability of Regulator and Auditor}

CSRC can reduce its auditing costs by providing more training to staff working in the area of monitoring and inspection. With enhanced ability, staff can work more efficiently, thus reducing cost.

\subsection{Regulate Auditing of Listed Companies}

Regulators need to impose extra pressure on auditors of listed companies and increase penalties for issuing false auditing reports. It will be more difficult for controlling shareholders to tunnel with independent auditors.

\subsection{Improve Corporate Governance of Listed Companies}

Corporate governance and regulation are complementary. Improving corporate governance will allow the CSRC to regulate more effectively. As the most important organizational framework in the modern enterprise system, improved corporate governance will improve efficiency of the firm and regulation.

\section{References}

Bing, G., \& Shu, Y. (2003). Share Division, Firm's Performance and Investor Protection. Management World, 5, 101-108.

Dyck, A., Volchkova, N., \& Zingales, L. (2008). The Corporate Governance Role of the Media: Evidence from Russia. Journal of Finance, 63(3), 1093-1135. http://dx.doi.org/10.1111/j.1540-6261.2008.01353.x

Friedman, E., Johnson, S., \& Mitton, T. (2003). Propping and Tunneling. Journal of Comparative Economics, 31(4), 732-750. http://dx.doi.org/10.1016/j.jce.2003.08.004

Gao, L., He, S., \& Huang, Z. (2006). Corporate Governance and Tunneling. Quarterly Journal of Economics, 7, 1157-1177.

Huang, Z. (2006). Shareholding Ratio, "Tunneling" Strategy and Full Circulation. Nankai Management Review, 1, 58-65.

Jensen, M. C., \& Meckling, W. H. (1976). Theory of the Firm: Managerial Behavior, Agency Costs and Ownership Structure. Journal of Financial Economics, 3(4), 305-360. http://dx.doi.org/10.1016/0304-405X(76)90026-X

Johnson, S., La Porta, R., Lopez-de-Silanes, F., \& Shleifer, A. (2000). Tunneling. American Economic Review, 90(2), 22-27. http://dx.doi.org/10.1257/aer.90.2.22

La Porta, R., Lopez-de-Silanes, F., \& Shleifer A. (1999). Corporate Ownership around the World. Journal of Finance, 54(2), 471-517. http://dx.doi.org/10.1111/0022-1082.00115

La Porta, R., Lopez-de-Silanes F., Shleifer, A., \& Vishny, R. (2000). Investor Protection and Corporate Governance. Journal of Financial Economics, 58(1-2), 3-27. http://dx.doi.org/10.1016/S0304-405X(00)00065-9

La Porta, R., Lopez-De-Silanes, F., Shleifer, A., \& Vishny, R. (2002). Investor Protection and Corporate Valuation. Journal of Finance, 57(3), 1147-1170. http://dx.doi.org/10.1111/1540-6261.00457 
Lins, K. V. (2003). Equity Ownership and Firm Value in Emerging Markets. Journal of Financial \& Quantitative Analysis, 38(1), 159-184. http://dx.doi.org/10.2307/4126768

Liu, F., \& He, J. (2004). Ownership Structure and Large Shareholders' Choice of Realizing Profits. China Accounting Review, 1, 141-158.

Luo, D., \& Tan, Q. (2007). Market Environment and "Tunneling" Behavior by Controlling Shareholders. Accounting Research, 4, 69-74.

Shleifer, A., \& Wolfenzon, D. (2002). Investor Protection and Equity Markets. Journal of Financial Economics, 66(1), 3-27. http://dx.doi.org/10.1016/S0304-405X(02)00149-6

Tang, Z., \& Jiang, W. (2002). An Empirical Analysis of Expropriation by Large Shareholders of Listed Companies in China. Economic Research, 2, 44-50.

Williamson, O. (1993). Calculativeness, Trust, and Economic organization. Journal of Law and Economics, 36, 453-486. http://dx.doi.org/10.1086/467284

Xiao, M., \& Shen, Y. (2008). Do Cross-Regional Listed Companies Have Lower Equity Costs? Journal of Financial Research, 10, 93-103.

Yan, Z., \& Zhou, Q. (2007). Listed Companies' Conflict of Interest and Regulation of Listed Companies in the Post Share Division Era. Reform of Economic System, 1, 46-50.

\section{Notes}

Note 1. Tunneling refers to the transfer of resources out of a company for the benefit of controlling shareholders. This is normally done at the expense of minority shareholders. Johnson, S., R. La Porta, et al. (2000). "Tunneling." American Economic Review 90(2): 22.

Note 2. To simplify the model, we assume the absolute value of reputation gain and loss is equal. The results of the model will be the same even if we assume the reputation gain and loss are of different value.

Note 3. ST will be added on the code of a listed company if it has been making loss for two consecutive years. If a listed company has been making loss for three consecutive years, it may be delisted. 